\title{
Molecular identification of Mycobacterium avium subspecies paratuberculosis in oral biopsies of Crohn's disease patients
}

\author{
Paola Molicotti ${ }^{{ }^{*}+}$, Antonio M Scanu ${ }^{2 \dagger}$, Aurea Lumbau ${ }^{3}$, Sara Cannas ${ }^{1}$, Alessandra Bua ${ }^{1}$, Pietrina Lugliè ${ }^{3}$ \\ and Stefania Zanetti ${ }^{\top}$
}

\begin{abstract}
Oral lesions may be found in patients with Crohn's disease (CD), in a percentage up to 20\%. The aim of this study was to investigate a possible relationship between Mycobacterium avium subsp. paratuberculosis (MAP) and oral lesions in CD patients. 23 oral biopsies were examined performing IS900 Nested PCR; 9 of them were positive: 8 from CD patients and 1 from a control. Our purpose is to go on with this study, amplifying the number of subjects examined and testing subjects with oral lesions related to diseases other than $C D$ to verify the specific association between MAP and oral lesions in CD patients.
\end{abstract}

Keywords: MAP, Oral lesion Crohn, Oral granulomatous lesions, PCR IS900

\section{Background}

Crohn's disease $(\mathrm{CD})$ is a chronic-recurring inflammatory bowel disease that may affect every part of the gastrointestinal tract. Oral lesions may be found in patients with full-blown intestinal CD or may represent the onset. It has been discussed about which lesions may be considered pathognomonic of $\mathrm{CD}$ or secondary nonspecific lesions: a histopathologic confirmation of the diagnosis is required (Figures 1 and 2). Several authors have hypothesized an involvement of Mycobacterium avium subspecies paratuberculosis (MAP) in CD in genetically predisposed subjects $[1,2]$. The aim of this study was to evaluate the presence of MAP in oral lesions of CD patients.

\section{Methods}

23 Italian subjects were examined; a first group was composed of $12 \mathrm{CD}$ patients, while a second one was made up of 11 healthy subjects. Subjects of both groups presented "aphthous type" oral lesions. Specimens were collected in physiological solution and sent to the Laboratory of Mycobacteriology of University of Sassari. The specimens were inoculated in liquid medium MGIT (Becton Dickinson), added with Mycobactin J at the concentration of $1 \mu \mathrm{g} / \mathrm{ml}$ and in solid medium Herrold's (Becton Dickinson). After DNA extraction following standard protocols, Nested PCR IS900 was carried out (Table 1) [3]. Nested PCR was always performed with internal controls in order to avoid false positive results. Moreover, all the surfaces and the instruments used to perform PCR were cleaned every time, before and after their use with DNA Cleaner (DIATECH) to avoid crosscontamination. Nested PCR on biopsy samples was performed three times, and every time the results were the same. Statistical analysis was performed with Fisher's exact test (Graph-pad Scientific calculator, $\mathrm{p}<0.05$ was considered significant).

* Correspondence: molicott@uniss.it

${ }^{\dagger}$ Equal contributors

'Dipartimento di Scienze Biomediche - Microbiologia Sperimentale e Clinica, Università degli Studi di Sassari, Viale San Pietro 43/b, 07100 Sassari, Italy

Full list of author information is available at the end of the article 

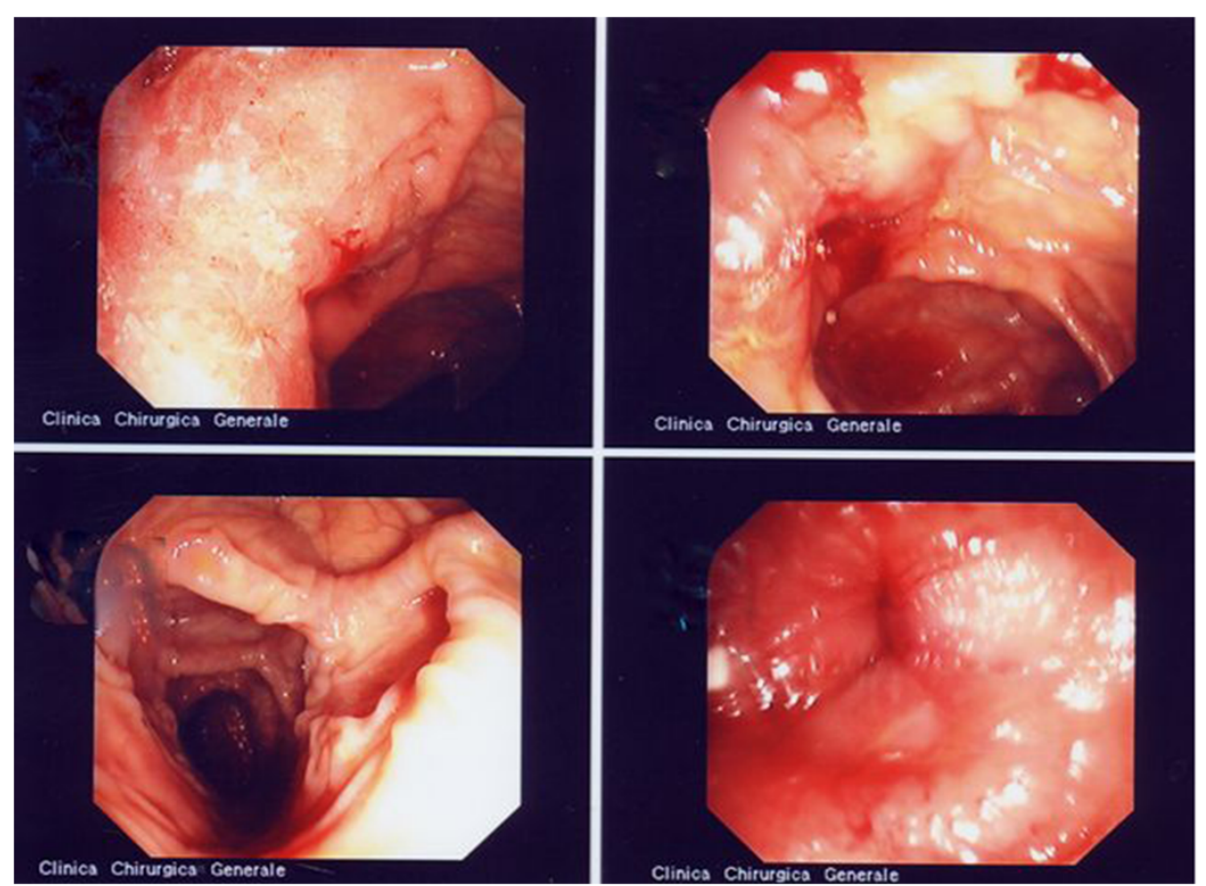

Figure 1 Exulcerative lesions in ileal Crohn initially active with wall thickness, oedema with the bottom of afta covered with fibrin of the exulceration. Istologic findings pathognomonic for CD.

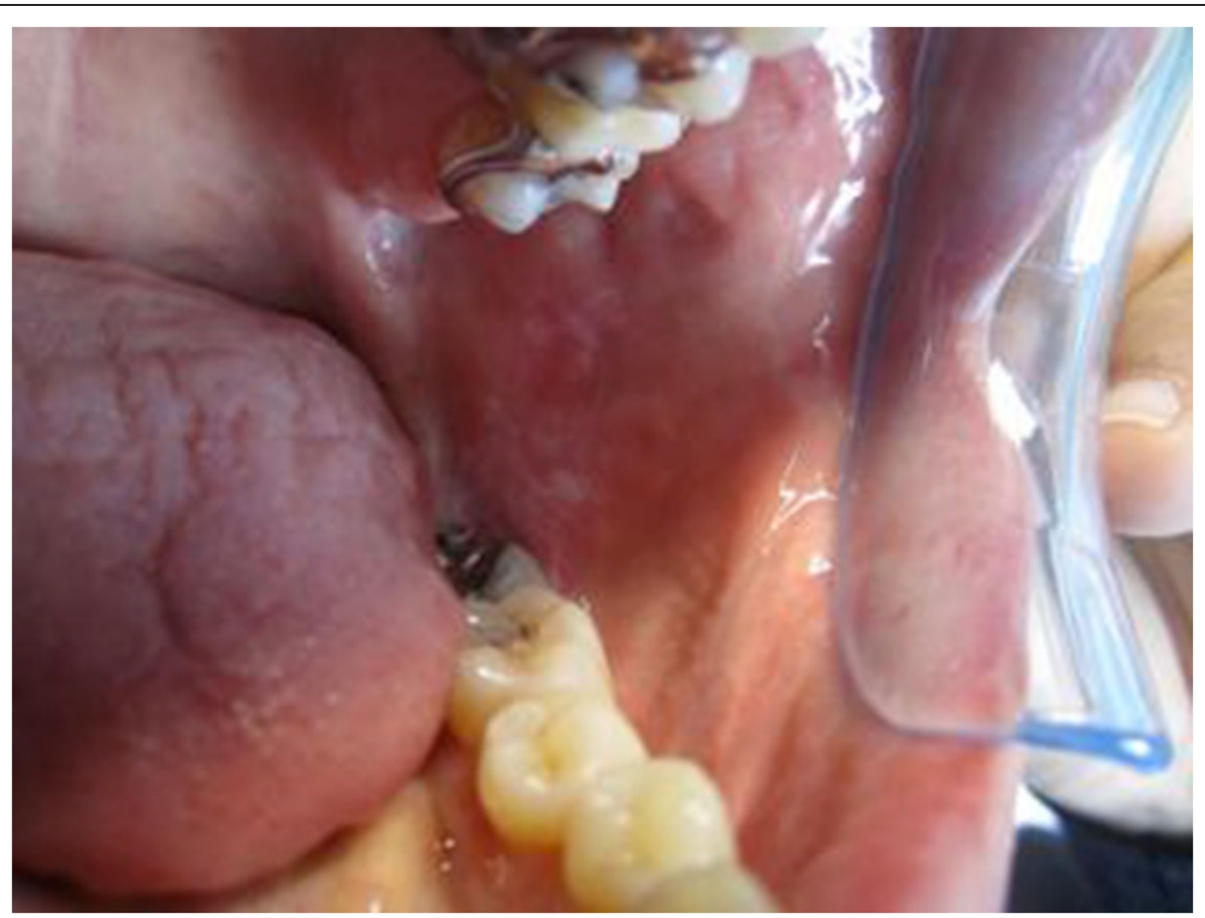

Figure 2 Small aphthous exulcerative lesions in CD patients with wall thickness, oedema and fibrina deposit in the base of ulcer. Istologic findings of CD. 
Table 1 Results of Nested PCR IS900

\begin{tabular}{|c|c|c|c|c|}
\hline \multirow[t]{2}{*}{ Patients } & \multicolumn{2}{|c|}{ IS900 Positive } & \multicolumn{2}{|c|}{ IS900 Negative } \\
\hline & Women & Men & Women & Men \\
\hline$C D$ & 2 & 6 & 3 & 1 \\
\hline Control & 0 & 1 & 4 & 6 \\
\hline
\end{tabular}

\section{Results and discussion}

The 12 patients affected by CD, 5 women and 7 men, aged 16-35 presented a full-blown ileal disease. $50 \%$ of patients $(6 / 12)$ presented only an ileal location, 33\% (4/12) showed a concomitant rectal location, while $17 \%(2 / 12)$, had also a duodenal location. In $67 \%$ of them $(8 / 12)$ the oral lesions were compatible with an oral location of the disease, while in the remaining $33 \%(4 / 12)$ they were not. The subjects of the control group, 4 were women and 7 men, aged 4565 , had not any clinical sign of IBD or other gastroenteric disease. Cultural examination after 6 months was negative for all the biopsies. Nested PCR was positive in 9 biopsies: 8 from patients affected by CD and 1 from a subject of the control group (Figure 3 and Table 1). In the $8 \mathrm{CD}$ patients the ulcerative lesions were compatible with oral CD. Histological examination was compatible with ulcerative lesions characterized by lymphoplasmacellular and histiocytarian chronic phlogosis. Neither cases of cobblestoning, nor cases in which swelling of lymph node chains were observed, while in 3 patients a mild lip swelling was observed. In $4 \mathrm{CD}$ patients with a negative Nested PCR, oral ulcers were small secondary lesions characterized by a little flat exulceration with hyperaemic edge and intensely painful. Histological examination was compatible with small abscessual foci or nonspecific phlogosis with chorion oedema and neutrophilic cells infiltration.

The subjects of the control group presented an aphthous-like lesion with hyperaemic edge and a bottom covered with fibrin, without a histological picture compatible with $\mathrm{CD}$. In the remaining 10 control subjects with a negative Nested PCR, lesions varied from simple gingivites to aphthous gingival-stomatites or to small aphtha-like exulcerative lesions; in no case the lesions showed a CDlike histology. Statistical analysis showed a significative difference between the positive results of Nested PCR obtained in the first group and in the control one ( $p=0,0094$ two tailed). The molecular methods specific for MAP allow its identification from intestinal biopsies of CD patients and represent the gold standard to distinguish MAP from other mycobacteria [4-7]. Oral lesions in CD patients occur in a percentage comprised between $0.5 \%$ and $20 \%$ [8-10] and it has been seen that some aphthous-like lesions may be specific indexes of the disease $[11,12]$. The cultures resulted negative probably due to difficulties in the isolation of MAP. The negative results of the cultural examination may be explained with the difficulties in the isolation of MAP known in literature. Its growth is extremely slow (4-6 months) and strongly dependent on the addition of Mycobactin J in the culture medium. Instead, Nested PCR was positive in 8 of $12 \mathrm{CD}$ patients and in 1 healthy subject. Positiveness associated to the control subject requires further investigation to ascertain if the oral lesion is an initial sign of the disease. We found a highly significant association between Mycobacterium avium subsp. paratuberculosis and oral biopsies in CD patients, and considering that these lesions may occur at the beginning of $\mathrm{CD}$ and that MAP could be the etiological agent, its quick identification might represent an important diagnostic tool.

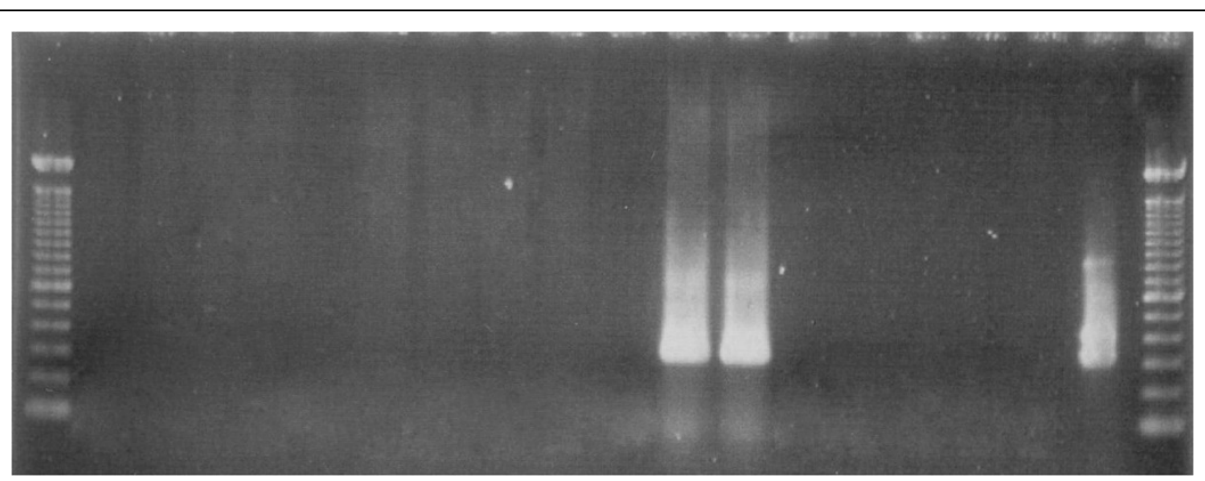

Figure 3 Results of IS900 PCR testing for Mycobacterium avium subsp. paratuberculosis in the patient CD with con oral lesions. The results are consistent with an extensive Mycobacterium avium subsp. paratuberculosis infection. Lanes: 1 and 20 Markers 100 bp; Lane 2: negative control; Lane 19: positive PCR control; Lanes 12 and 13: positive samples. 


\section{Competing interests}

The authors declare that they have no competing interest.

\section{Authors' contributions}

PM was involved in the experimental design and drafted the manuscript. AS was involved in the experimental design and helped to draft the manuscript. AL participated in the design of the study. SC carried out the samples' analysis. AB provided writing assistance. PL and SZ conceived the study, and participated in its design and coordination and helped to draft the manuscript. All authors read and approved the final manuscript.

\section{Author details}

${ }^{1}$ Dipartimento di Scienze Biomediche - Microbiologia Sperimentale e Clinica, Università degli Studi di Sassari, Viale San Pietro 43/b, 07100 Sassari, Italy. ${ }^{2}$ Dipartimento di Medicina Clinica Sperimentale ed Oncologica - Sezione Clinica Chirurgica, Università degli Studi di Sassari, Sassari, Italy. ${ }^{3}$ Dipartimento di Scienze Chirurgiche, Microchirurgiche e Mediche. Università degli Studi di Sassari, Sassari, Italy.

Received: 18 March 2013 Accepted: 4 June 2013

Published: 10 July 2013

\section{References}

1. Scanu AM, Bull TJ, Cannas S, Sanderson JD, Sechi LA, Dettori G, Zanetti S, Hermon-Taylor J: Mycobacterium avium subspecies paratuberculosis infection in cases of irritable bowel syndrome and comparison with Crohn's disease and Johne's disease: common neural and immune pathogenicities. J Clin Microbiol 2007, 45(12):3883-3890.

2. Taylor H: Mycobacterium avium subspecies paratuberculosis, Crohn's disease and the Doomsday scenario. Gut Pathog 2009, 1(1):15.

3. Bull TJ, Hermon-Taylor J, Pavlik II, El-Zaatari F, Tizard M: Characterization of IS900 loci in Mycobacterium avium subsp. paratuberculosis and development of multiplex PCR typing. Microbiology 2000, 146(Pt 12):3285.

4. Chiodini RJ: Crohn's disease and the mycobacterioses: a review and comparison of two disease entities. Clin Microbiol Rev 1989, 2(1):90-117.

5. Bull TJ, Sidi-Boumedine K, McMinn EJ, Stevenson K, Pickup R, Hermon-Taylor $\mathrm{J}$ : Mycobacterial interspersed repetitive units (MIRU) differentiate Mycobacterium avium subspecies paratuberculosis from other species of the Mycobacterium avium complex. Mol Cell Probes 2003, 17(4):157-164.

6. Sechi LA, Mura M, Tanda F, Lissia A, Solinas A, Fadda G, Zanetti S: Identification of Mycobacterium avium subsp. paratuberculosis in biopsy specimens from patients with Crohn's disease identified by in situ hybridization. J Clin Microbio/ 2001, 39(12):4514-4517. Erratum in: J Clin Microbiol 2002: Feb;40(2):739. Manuela, M [corrected to Mura, M]; Francesco, T [corrected to Tanda, F]; Amelia, L [corrected to Lissia, A]; Antonello, S [corrected to Solinas, A]; Giovanni, F [corrected to Fadda, G]; Stefania, Z [corrected to Zanetti, S].

7. Autschbach F, Eisold S, Hinz U, Zinser S, Linnebacher M, Giese T, Löffler T, Büchler MW, Schmidt J: High prevalence of Mycobacterium avium subspecies paratuberculosis IS900 DNA in gut tissues from individuals with Crohn's disease. Gut 2005, 54(7):944-949.

8. Sanderson J, Nunes C, Escudier M, Barnard K, Shirlaw P, Odell E, Chinyama C, Challacombe S: Oro-facial granulomatosis: Crohn's disease or a new inflammatory bowel disease? Inflamm Bowel Dis 2005, 11(9):840-846.

9. Harty S, Fleming P, Rowland M, Crushell E, McDermott M, Drumm B, Bourke B: A prospective study of the oral manifestations of Crohn's disease. Clin Gastroenterol Hepatol 2005, 3(9):886-891.

10. Pittock S, Drumm B, Fleming P, McDermott M, Imrie C, Flint S, Bourke B: The oral cavity in Crohn's disease. J Pediatr 2001, 138(5):767-771.

11. Daley TD, Armstrong JE: Oral manifestations of gastrointestinal diseases. Can J Gastroenterol 2007, 21(4):241-244.

12. Lourenço SV, Hussein TP, Bologna SB, Sipahi AM, Nico MM: Oral manifestations of inflammatory bowel disease: a review based on the observation of six cases. J Eur Acad Dermatol Venereol 2010, 24(2):204-207.

doi:10.1186/1757-4749-5-18

Cite this article as: Molicotti et al.: Molecular identification of Mycobacterium avium subspecies paratuberculosis in oral biopsies of Crohn's disease patients. Gut Pathogens 2013 5:18.

\section{Submit your next manuscript to BioMed Central and take full advantage of:}

- Convenient online submission

- Thorough peer review

- No space constraints or color figure charges

- Immediate publication on acceptance

- Inclusion in PubMed, CAS, Scopus and Google Scholar

- Research which is freely available for redistribution

Submit your manuscript at www.biomedcentral.com/submit
C BioMed Central 